\title{
Impact of enhanced Osmia bicornis (Hymenoptera; Megachilidae) 1 populations on pollination and fruit quality in commercial sweet 2 cherry (Prunus avium (L)) orchards
}

by Ryder, J.T., Cherrill, A., Prew, R., Shaw, J., Thorbek, P. and Walters, K.F.A.

Copyright, publisher and additional Information: This is the author's accepted manuscript. The final published version (version of record) is available online via Taylor \& Francis

Please refer to any applicable terms of use of the publisher.

DOI: https://doi.org/10.1080/00218839.2019.1654062

Ryder, J.T., Cherrill, A., Prew, R., Shaw, J., Thorbek, P. and Walters, K.F.A. 2019. Impact of enhanced Osmia bicornis (Hymenoptera; Megachilidae) 1 populations on pollination and fruit quality in commercial sweet 2 cherry (Prunus avium (L)) orchards. Journal of Apicultural Research. 
1 Impact of enhanced Osmia bicornis (Hymenoptera; Megachilidae)

2 populations on pollination and fruit quality in commercial sweet

3 cherry (Prunus avium (L)) orchards

4 Jordan T. RYDER ${ }^{1}$, Andrew CHERRILL ${ }^{1}$, Richard PREW ${ }^{1}$, Jenna SHAW ${ }^{1}$, Pernille THORBEK $^{2 *}$, Keith FA WALTERS ${ }^{1}$.

6

7

8

9

2. Syngenta, Jealott's Hill, Bracknell, Berkshire, RG42 6EY, UK Germany

Short Title: Osmia bicornis pollination of Prunus avium.

\section{Abstract}

17 The impact on pollination of supplementing wild pollinators with commercially reared Osmia bicornis in commercial orchards growing the self-fertile sweet cherry variety

19 "Stella" was investigated in each of two years. The quality characteristics used by

20 retailers to determine market value of fruit were compared when insect pollination was by wild pollinators only, or wild pollinators supplemented with $O$. bicornis released at 
recommended commercial rates. No effect of treatment on the number of fruit set or subsequent rate of growth was recorded. However, supplemented pollination resulted in earlier fruit set when compared to pollination by wild pollinators alone and offered the potential benefit of a larger proportion of the crop reaching optimum quality within a narrower time range, resulting in more consistent produce. Retailers use five key quality criteria in assessment of market value of cherries (the weight of individual fruit, width at the widest point, fruit colour, sugar content and firmness). Price paid to growers depends both on meeting the criteria and consistency between fruit in these characteristics. In both years, the commercial criteria were met in full in both treatments, but harvested fruit following supplemented pollination were consistently larger and heavier compared to those from the wild pollinator treatment. In the year where supplemented pollination had the greatest impact on the timing of fruit set, fruit size and sugar content were also less variable than when pollination was by wild species only. The implications for the commercial use of $O$. bicornis in cherry orchards are considered.

\section{Keywords}

38 Solitary bee/ Sweet Cherry/ Fruit set/ Fruit quality/ Osmia bicornis/ Pollination

\section{Introduction}

41 Insect pollination is a key ecosystem service, with estimates valuing it at $£ 430$ million per 42 annum within UK agricultural systems alone (Vanbergen, Heard, Breeze, Potts, \& 43 Hanley, 2014). Insect pollinators (including wild bees) account for $35 \%$ of global crop 
44 pollination (Garibaldi et al., 2013) but a decline in bee populations has been observed 45 over the last 60 years (Potts et al., 2010) and linked to a range of drivers (Neumann \& 46 Carreck, 2010; Potts et al., 2010). Although the lack of coordinated monitoring 47 programmes results in their being only limited firm evidence for widespread losses in 48 most pollinator groups, the strongest conclusions can be drawn from data generated in 49 Europe and North America where well studied groups displaying a decline include honey bees and bumblebees. Fragmentary evidence for other groups is available, however, and quantitative synthesis of local scale studies has revealed a wide scale pattern of loss of pollinator richness and abundance (Ricketts et al., 2008; Winfree et al., 2009) that collectively suggests that a widespread decline is occurring in many regions of the world

54 (Potts et al., 2010). The decline is more severe amongst specialist feeding species with many generalist feeders less affected due to their association with a wider range of plant species (Neumann \& Carreck, 2010; Potts et al., 2010). It has been suggested that wild pollinator decline has had a greater impact on pollination of high value fruit crops such as top fruit orchards than on other crops, and to address shortfalls in pollination services in orchards wild pollinators are commonly supplemented with commercially managed species such as Apis mellifera (Allsopp, de Lange, \& Veldtman, 2008; Breeze, Bailey, Balcombe, \& Potts, 2011, Garibaldi et al., 2013). Against a background of increasing costs associated with such managed bees and the decline in wild pollinators (Allsopp et al., 2008; Breeze et al., 2011; Potts et al., 2010), interest in the potential commercial use of alternative organisms to supplement pollination is rising.

Solitary bees of the genus Osmia have been shown to be an effective alternative to existing commercial pollinators in several fruit crops. Osmia cornifrons is used for commercial apple and cherry pollination in China (Batra, 1978) and Japan (Bosch \& 
68 Kemp, 2002; Sekita, 2000; Sekita \& Yamada, 1993) and Osmia lignaria is used in orchards in the USA (Morales-Ramos, Rojas, \& Shapiro-Ilan, 2013). In Europe use of Osmia cornuta was developed successfully for orchard pollination, and this was followed by its introduction to California in the 1980s to pollinate almond crops (Torchio \& Asensio, 1985). Use of O. cornuta as a pollinator for blackberry (Rubus fruticosus L.) has also been investigated in confined environments in Italy, and heavier berries bearing more drupelets were produced when $O$. cornuta were used than in systems relying on self or wind pollination (Pinzauti et al., 1997). Osmia bicornis (Linnaeus, 1758) (previously Osmia rufa) has been used in European orchards from the 1970s, since being developed as a pollinator for fruit trees (including sour cherries) and other crops such as strawberries and oilseed rape (Hansted, Grout, Toldam-Andersen, \& Eilenberg, 2014; Sedivy \& Dorn, 2014). Although positive effects on both yield and quality (compared to background pollination by wild pollinators alone) have been reported when this species is released in later flowering fruit crops, more work is needed to determine its efficacy in earlier flowering crops such as cherries.

O. bicornis is a widely distributed univoltine, polylectic species, ranging from Scandinavia to the Mediterranean (Lhomme, 2014; O’Toole, 2000). It is active in Europe from March onwards in most years (O’Toole, 2000; Raw 1972), and commercial rearing techniques ensure the availability of adults for release sufficiently early in the year to pollinate earlier flowering orchard crops, such as cherries, at a time when fewer alternative wild pollinators are available (Gruber, Eckel, Everaars, \& Dormann, 2011).

In the UK both self-fertile and self-sterile varieties of sweet cherry (Prunus avium (L.)) flower in late March or early April. Rapid ovule degeneration occurs during flowering 
and the majority of self-fertile varieties that are grown in commercial orchards (e.g. Stella) are thought to benefit from supplementary pollination by insects (Delaplane \& Mayer, 2000; Lane, 1979). Early pollination has been shown to influence fruit set, and it has been suggested that flowers pollinated later in the blossom period may show a reduction in eventual fruit quality (Mayer, Rathbone, \& Miliczky, 1987; Ughini \& Roversi, 1993). Thus pollinators that are actively foraging during the short flowering period may play an important role in maintaining yield or quality of produce (Delaplane \& Mayer, 2000; Lane, 1979). The early flowering period of cherry trees coincides with activity of a restricted range of wild pollinators, amongst which some Bombus spp, Andrena spp and Osmia spp are thought to be of key importance (Guler \& Dikmen, 2013 Kirk \& Howes, 2012). These early flying wild species can increase fruit set and yield, even when honey bee colonies are placed in the orchards (Holzschuh, Dudenhöffer, \& Tscharntke, 2012).

Successful use of $O$. bicornis in commercial orchards is due in part to their morphology and, resulting from their nesting behaviour, the ease with which bees can be released and retained in a local area (Hansted et al., 2014; Sekita, 2000). Mason bees, such as $O$. bicornis, collect pollen on the scopa, which is located on the ventral surface of the gastrum. The location of the scopa increases the potential for contact with plant reproductive structures (Kuhn \& Ambrose, 1984) and pollen is easily dislodged resulting in effective transfer between flowers (Raw, 1972). Pollination can thus be achieved by fewer floral visits than is required by social bee species (Klein et al., 2012). The utility of $O$. bicornis is also enhanced because it requires a high number of foraging trips for provisioning of larval nest cells, and these trips are commonly completed within a short foraging range (Gathmann \& Tscharntke, 2002). These factors, coupled with the ability 
115 to fly in adverse weather (Güler \& Dikmen, 2013; Stone \& Willmer, 1989), increases the 116 potential of the species to act as an effective early season commercial pollinator.

117 Building on previous research, the crop production industry is currently considering the 118 potential of $O$. bicornis as a pollinator in oilseed rape, cherry orchards and soft fruit crops 119 such as strawberry (Bilinski \& Teper, 2004; Gruber et al., 2011; Teper \& Bilinski, 2009;

120 Wilkaniec \& Radajewska, 1996), and it has been shown that Osmia spp. can be effective 121 pollinators of crops in both confined and open environments (Pinzauti et al., 1997; Sedivy \& Dorn, 2014). Little information is available on the impact of $O$. bicornis in UK cherry (Prunus avium) production systems, however, and there is active debate regarding its potential efficacy. Research is therefore required to support optimisation of pollination services in this crop. This study investigates the hypothesis that supplementing pollination by $O$. bicornis release will increase the quality and yield of fruit in commercial cherry orchards.

\section{Materials and Methods}

Experiments were conducted in a mature commercial sweet cherry orchard (Prunus avium) in North Herefordshire, UK (SO583502), established in 2000 using the self-fertile cultivar "Stella" (RHS, 2016). The orchard is on south facing slopes with well-draining red Herefordshire soil, slightly acid loamy and clayey (Soilscapes, 2016), at 200m above sea level, and with a density of 1900 trees per hectare yielding a mean of 20 tonnes fruit per hectare. Trees were covered with open ended 100m polythene tunnels (poly-tunnels), each containing 2 rows separated by a narrow $(2 \mathrm{~m})$ grass strip with occasional herbaceous

137 flora including Taraxacum and Ranunculus spp. Normal commercial husbandry practice 
included opening tunnels during spring and summer, allowing access for pollinating insects during the flowering period.

\section{Experimental design and treatments}

A randomised design of four blocks each containing two treatment plots was established during early spring of 2015. The experiment was replicated in 2016. Each treatment plot occupied the central portion of a poly-tunnel and contained 50 trees (two rows of 25 trees). Fourteen days prior to bud burst (growth stage 2: 23rd March 2015, 21st March 2016; Chapman \& Catlin, 1976) the polythene sides of each plot were replaced with an insect-proof mesh covering. Mesh walls were also constructed to seal both open ends, thus facilitating release and containment of known numbers of $O$. bicornis.

Within each block, in one treatment plot (control) insect pollination relied on the wild pollinators trapped when mesh walls were constructed. In the second, wild pollinating insects were supplemented with commercially reared $O$. bicornis released at the standard rate ( 2 adult bees/tree) and timing recommended for cherry orchards by the supplier (Mason Bees Ltd., Shropshire, UK). Cocoons were removed from nest cells in early November the previous year and maintained under conditions of continuous dark and at a temperature varying between $2-4{ }^{\circ} \mathrm{C}$ until being moved to experimental plots. Two standard weatherproof release boxes $(18 \times 16 \times 8 \mathrm{~cm})$ were set at $1.5 \mathrm{~m}$ above the soil surface according to normal commercial practice. Boxes were positioned at distances equivalent to approximately one-third and two-thirds along the length of each of the plots, with an exit slit facing towards the South to allow escape of adult bees. Fourteen days before commencement of bud burst, fifty $O$. bicornis cocoons were placed in each release 
box and the adults allowed to emerge (60:40 female to male ratio). To confirm the total

number of adult $O$. bicornis that were active during flowering in each plot, empty cocoons were counted at 7-day intervals until all had emerged. Cocoons from which adult bees failed to emerge within the expected time period were removed and replaced.

With the exception of the treatment-specific procedures, all crop husbandry activities were identical in all plots and followed normal commercial practice for the orchard.

\section{Assessments}

Temperature - Temperatures within each treatment plot were recorded with a handheld digital thermometer at each assessment visit (TPI Digital Pocket Thermometer, Crawley UK). Three measurements were recorded in each treatment/replicate at each visit, at 10:00, 13:00 and 15:00.

Abundance of wild pollinators - The abundance of wild pollinating fauna was established by taking sweep net samples in all plots on each of five days during the flowering period of the orchard. Sampling was conducted while walking at a standard speed (circa $2 \mathrm{~ms}^{-1}$ ) along the full length of the central strip between the 2 rows of cherry trees, before the catch was transferred to a sealed plastic bag and returned to the laboratory where it was stored in a freezer at $-20^{\circ} \mathrm{C}$ until processing. To take account of diurnal activity cycles of different pollinators, sampling was undertaken during three periods (08:00-10:00, 11:30-13:30, 15:00-17:00), and was replicated on each of five days during the blossom period. Counts were only taken on days when temperatures 
were favourable for pollinator activity $\left(>12^{\circ} \mathrm{C}\right)$, based on the temperature assessments described above.

184 As available resources precluded identification of all individuals to species, the insects caught were recorded under six categories, wild (non-O.bicornis) solitary bees, bumblebees (Bombus spp.), honey bees (Apis mellifera), hoverflies (Syrphidae), "other" 187 diptera, and "other" insects (Hymenoptera (mainly parasitoids, Coleoptera and 188 Neuroptera). The assessment therefore recorded the groups found in each sample that potentially contributed to wild pollination, but as counts included both pollinating and some non-pollinating species it is likely that they overestimated the cumulative contribution of wild pollinators to cherry pollination in the treatment tunnels.

Fruit set and fruit drop - Prior to the start of bud burst (growth stage 2, Chapman \& Catlin, 1976), 10 trees were selected at random in each treatment/replicate (five from each row), and a branch from mid-canopy level was selected for assessments and labelled. The number of buds on the distal $50 \mathrm{~cm}$ portion of each labelled branch was counted. After the end of all flowering (growth stage 7, Chapman \& Catlin, 1976) the number of developing fruit was counted, with further counts of fruit being taken on 5, 10, 16, 23 June and 1 July in 2015, and 7, 12, 19, 24 June and 3 July 2016. The last count of fruit was taken at the commencement of ripening.

Fruit growth - The terminal fruit cluster from labelled branches was identified and the width at the widest point of each individual fruit was measured with digital callipers (Sealey, Suffolk UK). Measurements were repeated at weekly intervals (2015: 5, 10, 16, 23 June, 1 July; 2016: 7, 12, 19, 24 June and 3 July). 
Fruit quality - Fruit quality assessments were taken within 2 days of the harvest date for 205 the orchard $\left(10^{\text {th }}\right.$ July $2015 ; 9^{\text {th }}$ July 2016$)$ with a minimum of 40 fruit sampled from each 206 plot. Fruit were harvested by commercial pickers, placed carefully in labelled punnets 207 and returned immediately to the on-site cold storage facility. Five quality measurements 208 were made for each individual fruit (weight), width at the widest point, fruit colour, sugar content and consistency (firmness), using the standard equipment and approaches used in commercial quality assessment procedures for determining market value (Sainsbury’s

211 Supermarkets Ltd, 2015). Weight was assessed using a 50g spring scale (Pesola Light212 Line, Schindellegi, Switzerland), width using the callipers described above, fruit colour 213 on the industry standard scale of 1 (light fruit) to 7 (dark fruit) using the standard 214 commercial colour guide (Centre Technique Interprofessionel des Fruits et Legumes, 215 Paris France), and sugar content (percentage brix) by piercing the skin of the fruit and 216 squeezing the juice onto the receptor of an Atago digital refractometer (Atago, Tokyo, 217 Japan). Fruit consistency was assessed using a digital firmness penetrometer (Agro 218 Technologie, Serqueux, France) by averaging two measurements of fruit consistency 219 taken at the widest point of the cherry (separated by 180 Degrees). In each measurement 220 consistency was recorded as the pressure required to penetrate the flesh of the cherry and expressed (according to normal commercial practice) as percentage of the maximum 222 pressure that could be exerted by the penetrometer, which corresponded to a pressure of $223806 \mathrm{~g}$ (Agrosta, 2015). Penetrometer assessments were only made in 2015 due to an 224 equipment failure in 2016. 
227 Statistical analysis was conducted using R version i 386 3.2.3 (R core team, 2012). All 228 data was checked for normality and Log transformations applied where necessary. Factor 229 reduction was conducted allowing for the removal of non-significant terms and 230 interactions in order to reach the minimum adequate model for all statistical tests 231 conducted. During factor reduction, ANOVA between models was conducted to verify 232 that the validity of the statistical model was not affected.

233 Temperature data consisted of a continuous response variable with categorical 234 explanatory variables, thus a two-way analysis of variance (ANOVA) was utilised.

235 Due to the low numbers of insects recorded in assessments of wild pollinators, paired $t$ 236 tests were used in comparisons of both numbers caught in different treatments, and to 237 investigate differences between the overall numbers caught in 2015 and 2016.

238 The number of buds and number of fruit set per unit length of branch was count data and 239 thus was analysed using GLM with Poisson error structure. Where residual deviance was 240 found to be greater than the degrees of freedom a Quasi-Poisson error structure was 241 applied. The proportion of fruit set was analysed with a GLM with a Binomial error 242 structure.

243 Impact of treatment on cherry development (fruit size over time) consisted of both a 244 continuous and categorical response variable, due to this an ANCOVA was used for 245 analysis.

246 For fruit quality post-harvest assessments, data for width, weight, firmness and brix were 247 all subjected to ANOVA and Tukey post hoc test to assess the impact of treatment. 
248 Fruit colour data was collected on an ordinal scale and differences between treatments

249 were investigated using a Kruskal-Wallis one-way analysis of variance and post-hoc

250 Dunn test.

251 For all post-harvest quality assessments a Fisher's $F$-test was conducted to investigate

252 whether the variability of fruit differed between treatments.

253

254 Results

255 For all assessments, block and plot were found to be non-significant in both years and 256 therefore removed in both factor reduction and creation of the minimum adequate model.

257 Temperature - During the creation of the minimum adequate model, treatment was found 258 to be non-significant and thus removed from analysis. Thus, there was no difference in 259 temperature between treatment blocks. Temperature varied significantly between dates in 260 both $2015(F=2.87$, d.f. $=4,91, \mathrm{p}<0.05)$ and $2016(F=700.90$, d.f. $=1,69, \mathrm{p}<0.001)$

261 reflecting the transition from spring to summer. Higher temperatures were recorded in 2622016 than $2015(F=279.05$, d.f. $=2,160, \mathrm{p}<0.001)$.

263 Wild pollinators - Very few wild pollinators from any of the six groups (wild (non- $O$.

264 bicornis) solitary bees, bumblebees (Bombus spp.), honey bees (Apis mellifera),

265 hoverflies (Syrphidae), “other" diptera, and "other” insects), were recorded in sweep net

266 samples taken in either year (Table 1). The results of paired t-tests show no significant

267 differences between treatments in the numbers of insects caught in either year (2015: $t$

$268=-1.67$, d.f. $=3, \mathrm{p}>0.05 ; 2016: t=-1.71$, d.f. $=3, \mathrm{p}>0.05)$. Although very low in both 

$7, \mathrm{p}<0.001)$.

271

272 Table 1 Here

273

274 Fruit set

275 Bud counts -There were more buds per branch in 2015 than in $2016(t=11.97$, d.f $=233$, 276 $\mathrm{p}<0.001$ ), but there were no significant differences between treatments in the number of

277 buds in either year $(2015: t=0.24$, d.f. $=152, \mathrm{p}>0.05 ; 2016: t=1.056$, d.f. $=79, \mathrm{p}>0.05$, 278 Figure 1A, B).

Proportion fruit set - In 2015 the proportion of buds from which fruit was set was lower 283 than in $2016(\mathrm{z}=-29.61$, d.f. $=233, \mathrm{p}<0.001)$. Differences between treatments were not 284 consistent between years. In 2015, the proportion of buds from which fruit was set was 285 not significantly different between wild pollinator and Osmia supplemented treatments (z $286=0.19$, d.f. $=152, \mathrm{p}>0.05)($ Figure $1 \mathrm{C})$, but in 2016 the proportion of fruit set was lower 287 in Osmia supplemented treatments $(\mathrm{z}=-8.76$, d.f. $=79, \mathrm{p}<0.001)$ (Figure 1D).

288 Fruit counts - The results for fruit counts mirrored those for fruit set. In 2015 total fruit 289 count was lower than in $2016(t=-6.59$, d.f. $=233, \mathrm{p}<0.001)$ and total fruit counts were 
$291=0.19$, d.f. $=152, \mathrm{p}>0.5)$ (Figure 1E). In 2016 total fruit count was found to be lower in 292 Osmia supplemented treatments compared to the treatment with wild pollinators only $(t$ $293=-2.60$, d.f. $=79, \mathrm{p}<0.05)($ Figure $1 \mathrm{~F})$.

Fruit growth

296 Following log transformation to normalise the residuals of the data, fruit size increased 297 as a function of time $(t=46.0$, d.f. $=392, \mathrm{p}<0.001)$, but no significant differences were 298 found between treatments in the slopes of the lines describing the growth in width of cherries with time (Figure 2A). This interaction was therefore removed from the minimum adequate model for both 2015 and 2016.

There was, however, another significant effect of treatment on cherry development in $2015(F=8.94$, d.f. $=1,392, \mathrm{p}<0.01)$, with the intercepts of the regression line for Osmia supplemented treatments occurring earlier than that of the wild pollinator treatments $(\mathrm{t}=$ 225.8, d.f. $=392, \mathrm{p}<0.001)$, indicating that the mean time of commencement of fruit growth (following fruit set) was earlier in the Osmia supplemented treatments (Figure 2A). As pollination could only commence when flowers opened, which occurred at the same time in each treatment, the earlier mean time for commencement of fruit growth in 
the Osmia supplemented treatment suggests that pollination/fertilisation was completed

312 within a shorter time period when the bees were present.

313 A similar outcome was recorded in 2016 (Figure 2B). A significant effect of treatment

314 on cherry development was recorded $(F=100.56$, d.f. $=1,637, \mathrm{p}<0.001)$, with the

315 intercept for the Osmia supplemented treatment occurring significantly earlier than in the

316 wild pollinator treatment $(t=-165.71$, d.f. $=637, \mathrm{p}<0.001)$. All fruit widths increased as

317 a function of time $(t=37.56$, d.f. $=637, \mathrm{p}<0.001)$ (Figure 2$)$.

318

319

Post-harvest assessments

320

For all postharvest assessments block and plot were found to be non-significant in both

321 years and were removed in factor reduction. Due to only two treatments being available,

322 two tailed t-tests were utilised for analysis.

323

Weight and width - Fruit weight (2015: $t=5.66$, d.f. $=935, \mathrm{p}<0.001 ; 2016: t=3.46$, d.f. $=633, \mathrm{p}<0.001)$ and width $(2015: t=5.12$, d.f. $=934, \mathrm{p}<0.001 ; 2016: t=5.81$, d.f. $=$ 633, $\mathrm{p}<0.001)$ were both found to be higher in the Osmia supplemented treatment in both 2015 and 2016 (Figure 3). In 2015, however, there was no difference between treatments in the variability of individual cherry weight $(F=0.96$, d.f. $=501,434, \mathrm{p}>0.05)$ or width $(F=1.16$, d.f. $=501,433, \mathrm{p}>0.05)$. In 2016, the variability of fruit weight did not differ between treatments $(F=0.92$, d.f. $=306,385, \mathrm{p}>0.05)$, however width was found to be significantly more variable for fruit from the wild pollinators treatment compared to the fruit from the Osmia supplemented treatment $(F=1.35$, d.f. $=306,385, \mathrm{p}=<0.01)$. 
Sugar content and consistency - The cherries from all treatments met commercial requirements for sugar content (Sainsbury's Supermarkets Ltd, 2015), but Brix did not vary as a function of treatment in $2015(t=1.39$, d.f. $=934, \mathrm{p}>0.05)$ or $2016(t=1.16$, d.f. $=633, \mathrm{p}>0.05)($ Figure 4). Likewise firmness did not vary as a function of treatment in $2015(t=-1.28$, d.f. $=937, \mathrm{p}>0.05)$. Cherries from the wild pollinators and Osmia supplemented treatments were found to be equally variable for both sugar content and consistency in 2015 (Sugar content: $F=0.99$, d.f. $=502,432, \mathrm{p}>0.05$; consistency: $F=$ 0.88 , d.f. $=502,435, \mathrm{p}>0.05)$. In 2016 however, sugar content was found to be more

343 variable for fruit in the treatment with wild pollinators alone $(F=16.92$, d.f. $=306,385$, $344 \mathrm{p}<0.001)$.

\section{Figure 4 Here}

348 Colour - In 2015 and 2016 the colour of cherries varied between treatments (2015: $H=$ 34914.85 , d.f. $=1, \mathrm{p}<0.001 ; 2016: H=13.22$, d.f. $=1, \mathrm{p}<0.001)$. Fruit from Osmia supplemented treatments were darker in colour than those harvested from the wild

351 pollinator treatments in 2015, with this reversed in 2016 (Figure 5). However, fruit colour 352 scored lower (overall lighter) in 2015. The variability in colour of cherries did not differ 353 between treatments in either 2015 or $2016(2015: F=0.90$, d.f. $=502,435, \mathrm{p}>0.05$; 2016 : $F=1.00$, d.f. $=306,385, \mathrm{p}>0.05)$ and all required quality standards were met. 
Figure 5 Here

357

358

\section{Discussion}

359 The value of a sweet cherry crop at harvest is determined by yield, and quality 360 characteristics of the produce (including weight, size, colour, sugar content, and firmness 361 of the fruit), but simply meeting the set quality criteria is not sufficient to command the

362 highest prices. The consistency between fruit in key quality factors is also an important 363 consideration in commercial quality grading procedures determining the price paid to growers (Sainsbury's Supermarkets Ltd, 2015). In this study, all the quality characteristics of cherries from trees subjected to wild pollinator only treatments, and those exposed to both $O$. bicornis and wild pollinators, were within the ranges required by retailers.

368 Very low numbers of naturally occurring insects from the main pollinator groups were

369 recorded during flowering in the experiments conducted in both years, possibly reflecting 370 the earlier flowering time of cherry trees which does not coincide with the main 371 emergence period of most insects in the UK (Leather et al., 1995), and illustrating the 372 importance of the core self-fertilisation in this variety. Slightly higher numbers were 373 recorded in 2016 than in 2015, potentially linked to the higher ambient temperatures 374 during the flowering period in that year. The low numbers present reduced the risk of the 375 experiment being saturated by pollinators (i.e. achieving the maximum potential pollination irrespective of treatments imposed). Importantly, no significant differences 
were found between the numbers of these alternative pollinator species between treatments, which coupled with the low numbers present, gives confidence that they did not significantly affect the conclusions relating to the impact of $O$. bicornis.

Significant differences between treatments in some key characteristics were found. In both years fruit from the Osmia supplemented treatment were larger and heavier at harvest than those produced in the treatment with wild pollinators alone (Figure 3A, B). In 2015, no differences in fruit count were recorded between treatments (Figure 1E), indicating that the Osmia supplemented treatment resulted in a higher overall weight of cherries per unit branch length. This effect on total yield per unit branch length did not, however, occur in 2016, because fruit count was higher in the treatment with wild

387 pollinators alone (Fig $1 F$ ) counteracting the impact of larger individual fruit weight in the Osmia supplemented treatment (Fig 3B). We therefore found consistent effects on quality of individual fruit but not on total yield.

The rate at which the fruit grew following fruit set did not differ between treatments in either year. In both years, however, differences between treatments in the mean timing of fruit set were recorded. Trees in Osmia supplemented plots completed fruit set earlier than those with wild pollinators alone. Flowering commenced at the same time in both treatments, but pollination occurred more rapidly after bud burst in supplemented pollinator plots, and fruit set from all flowers on a tree was completed during a shorter time window, particularly in 2016 (Figure 2).

397 The shortening of the pollination window established in this study will result in greater synchronisation of cherry development within the crop, and it has been suggested that in other crops this contributes to the production of more uniform fruit size and quality at 
400 harvest (Freihat, Al-Ghzawi, Zaitoun, \& Alqudah, 2008; Hasegawa, Matsushita, \& 401 Kitajima, 2003; Stephenson, 1980). This study provides supporting evidence as improved 402 developmental synchrony of sweet cherries from pollinator supplemented plots can be 403 linked to fruit uniformity through significantly lower variability in fruit size and sugar 404 content. However, significant effects on sugar content were only recorded in the year in 405 which the largest differences between treatments in the length of the pollination window 406 occurred (2016), and further work is required to establish both the factors influencing 407 reliability of this outcome and its economic importance. In addition to improved market 408 value, growers have commented that benefits are also accrued if synchronisation results 409 in a larger proportion of the crop being ready for harvest within a narrow time range, 410 reducing the number of passes pickers need to make and associated labour costs.

411 An increase in fruit quality has been reported from a variety of crops when $O$. bicornis 412 contributes to pollination, partly a result of the mechanical action by which pollination is 413 achieved increasing the amount transferred (Klatt et al., 2014; Kuhn \& Ambrose, 1984; 414 Wilkaniec \& Radajewska, 1996). Higher levels of pollen deposition have been shown to 415 increase fruit set and quality in some Prunus species, and the high pollination efficiency 416 established by other studies may have contributed to the shortening of the pollination 417 window when O. bicornis was released (Kuhn \& Ambrose, 1984; Wilkaniec \& 418 Radajewska, 1996; Zhang, Tateishi, \& Tanabe, 2010). The importance of pollen 419 deposition may be amplified in "Stella" cherries, as other self-fertilising crop species, 420 such as blueberries, have been shown to require higher levels of pollen grain deposition 421 on the pistil when compared to cross pollinating varieties (Parrie \& Lang, 1992). If a similar higher level of pollen grain deposition on the pistil is beneficial to self-fertile varieties of sweet cherries, then the very low numbers of wild pollinators present in this 
study make it unlikely that this would be achieved without the supplementary O. bicornis, explaining the differences in fruit quality recorded between treatments.

426 Although significant differences between treatments in fruit colour were recorded, they were not consistent between years, suggesting other factors may have influenced the findings. In 2015 fruit colour (an indicator of ripening) was darker in Osmia supplemented plots compared to those with only wild pollinators (Figure 5). Treatments were harvested simultaneously, suggesting that the earlier completion of fruit set in Osmia supplemented treatments resulted in optimal harvest time being slightly earlier. However, results from 2016 suggested over-ripening of cherries in the wild pollinator treatment compared to those in the Osmia supplemented treatment. Fruit firmness (as measured using a penetrometer) is also, in part, related to degree of ripening if harvest is late, but did not vary as a function of treatment in 2015 (Figure 4). Further work is required to improve understanding of factors influencing these important quality characteristics to support decisions on time of harvesting.

In conclusion the release of $O$. bicornis in cherry orchard plots significantly increased the quality of fruit produced by shortening the pollination window, resulting in greater size and uniformity, important fruit quality characteristics, compared to pollination by wild insects alone. Although the impact of $O$. bicornis pollination in other UK crops such as strawberry (Klatt et al., 2014) and apples (Garratt \& Truslove, 2013) is more clearly established, the commercial potential of Osmia as a pollinator of cherries continues to be

444 debated (Hansted et al., 2014). Further research is required to investigate yield and quality

445 responses in both self-fertile and non-self-fertile $P$. avium varieties to support cost benefit analyses for its commercial use, and to enable comparisons with alternative managed 
447 pollinators. The effect of pollination treatment on shelf life of the crop, a key 448 characteristic for both growers and retailers, also warrants investigation.

\section{Acknowledgments}

451 This work was supported by a Biotechnology and Biological Sciences Research Council 452 (BBSRC) CASE Award under Grant BB/M503447/1. We thank Chris Whittles of the 453 Mason Bee Company Ltd. for his generous support in providing the solitary bees used in 454 this study, Andrew Hunt of Lower Hope Farm Ltd. for provision of the experimental site 455 and use of quality assessment equipment, and Keith Ward of Syngenta Ltd. for advice on statistical analysis.

457

\section{References}

1. Agrosta 2015. Agrosta®100 Field Digital Firmness Tester: https://www.agrotechnology.co.uk/arrow_htm_files/Agrosta_100_Field6.pdf

2. Aizen, M. A., \& Harder, L. D. (2009). The global stock of domesticated honey bees is growing slower than agricultural demand for pollination. Current Biology, 19(11), 915-918.

3. Allsopp, M. H., de Lange, W. J., \& Veldtman, R. (2008). Valuing insect pollination services with cost of replacement. PLoS One. 2008; 3(9): e3128. Published online 2008 Sep 10. doi: 10.1371/journal.pone.0003128 
4. Batra, S. (1978). Osmia cornifrons and Pithitis smaragdula, two Asian bees introduced into the United States for crop pollination. In D. M. Caron (Ed.), ISP 1978. Proceedings of the 4th International Symposium on Pollination (pp. 307312). Maryland Agricultural Experimental Station Miscellaneous Publication 1.

5. Biliński, M., \& Teper, D. (2004). Rearing and utilization of the red mason beeOsmia rufa L. (Hymenoptera, Megachilidae) for orchard pollination. Journal of Apicultural Science, 48, 69-74.

6. Bosch, J., \& Kemp, W. (2002). Developing and establishing bee species as crop pollinators: The example of Osmia spp. (Hymenoptera: Megachilidae) and fruit trees. Bulletin of Entomological Research, 92(1), 3-16.

7. Breeze, T., Bailey, A., Balcombe, K., \& Potts, S. (2011). Pollination services in the UK: How important are honeybees? Agriculture, Ecosystems and Environment. Agriculture, Ecosystems and Environment, 142, 137-143.

8. Chapman, P.J., \& Catlin, G.A. (1976). Growth Stages in Fruit Trees- From Dormant to Fruit Set. New York: New York State Agricultural Experiment Station, New York's Food and Life Sciences Bulletin, 58, 1-11.

9. Delaplane, K. S., Mayer, D. R., \& Mayer, D. F. (2000). Crop pollination by bees. New York, NY: CABI.

10. Freihat, N.M., Al-Ghzawi, A.M., Zaitoun, S., \& Alqudah, A. (2008). Fruit set and quality of loquats (Eriobotrya japonica) as effected by pollinators under subhumid Mediterranean. Scientia Horticulture, 117(1), 58-62. 
11. Fuchs, E.J., Quesada, M., \& Lobo, J. A. (2001). Pollen load size, reproductive success and progeny kinship of natural pollinated flowers of the tropical dry forest tree, Pachira quinata (Bombacaceae). American Journal of Botany, 88(11), $2113-2118$

12. Garibaldi, L. A., Steffan-Dewenter, I., Winfree, R., Aizen, M. A., Bommarco, R., Cunningham, S. A., ... Klein, A. M. (2013). Wild pollinators enhance fruit set of crops regardless of honey bee abundance. Science, 339(6127), 1608-1611.

13. Garratt, M., Truslove, L., Coston, D., Evans, R., Moss, E., Dodson, C., .... Potts, S. (2013). Pollination deficits in UK apple orchards. Journal of Pollination Ecology, 12(2), 9-14.

14. Gathmann, A., \& Tscharntke, T. (2002). Foraging ranges of solitary bees. Journal of Animal Ecology, 71(5), 757-764.

15. Gruber, B., Eckel, K., Everaars, J., \& Dormann, C. F. (2011). On managing the red mason bee (Osmia bicornis) in apple orchards. Apidologie, 42(5), 564-576.

16. Güler, Y., \& Dikmen, F. (2013). Potential bee pollinators of sweet cherry in inclement weather conditions. Journal of the Entomological Research Society, 15(3), 9-19.

17. Hansted, L., Grout, B. W., Toldam-Andersen, T. B., \& Eilenberg, J. (2014). An assessment of Osmia rufa (syn. bicornis) as a pollinator of the sour cherry (Prunus cerasus) cv. stevnsbaer in Eastern Denmark. Journal of Apicultural Research, 53(1), 177-182. 
18. Hasegawa. K., Matsushita, M., \& Kitajima, A. (2003). Effect of trunk strapping time on fruit set and quality in Persimmon cv. Matsumoto Wase fuyu, ISHA Acta Horticulturae, 601(12), 64-73.

19. Holzschuh, A., Dudenhöffer, J., \& Tscharntke, T. (2012). Landscapes with wild bee habitats enhance pollination, fruit set and yield of sweet cherry. Biological Conservation, 153, 101-107.

20. Kirk, W., \& Howes, F. (2012). Plants for bees. A Guide to the Plants that Benefit the Bees of the British Isles. Cardiff (UK): International Bee Research Association (IBRA).

21. Klatt, B.K., Holzschuh, A., Westphal, C., Clough, Y., Smit, I., Pawelzik, E., \& Tscharntke, T. (2014). Bee pollination improves crop quality, shelf life and commercial value. The Proceedings of the Royal Society B Biological Sciences, 281, 1-10.

22. Klein, A.M., Brittain, C., Hendrix, S.D., Thorp, R., Williams, N., \& Kremen, C. (2012). Wild pollination services to California almond rely on semi-natural habitat. Journal of Applied Ecology, 49, 723-732.

23. Kuhn, E. D., \& Ambrose, J. T. (1984). Pollination of "Delicious" apple by Megachilid bees of the genus Osmia (Hymenoptera: Megachilidae). Journal of the Kansas Entomological Society, 57(2), 169-180.

24. Lane, W. (1979). Pollination of self-fertile sweet cherry. Journal of Horticultural Science, 54, 87-89. 
25. Leather, S.R., Walters, K.F.A. \& Bale, J.S. (1993). Ecology of insect overwintering. Cambridge University Press, 255pp

26. Lhomme, P. (2014). Osmia bicornis. The IUCN Red List of Threatened Species 2014.http://www.iucnredlist.org/details/full/19198431/1,e.T19198431A2115492 6

27. Mayer, D., Rathbone, L., \& Miliczky, E. (1987). New ideas in cherry pollination. Proceedings of the Washington State Horticultural Association, 83, 228-229.

28. Morales-Ramos, J. A., Rojas, M. G., \& Shapiro-Ilan, D. I. (2013). Mass production of beneficial organisms: Invertebrates and Entomopathogens. London, UK: Academic Press.

29. Neumann, P., \& Carreck, N. L. (2010). Honey bee colony losses. Journal of Apicultural Research, 49(1), 1-6.

30. O'Toole, C. (2000). The red mason bee: Taking the sting out of bee-keeping. A practical guide to managing Osmia rufa as a pollinator in gardens, allotments, and orchards. Banbury, UK: Osmia Publications.

31. Parrie, E., \& Lang, G. (1992). Self-and cross-pollination affect stigmatic pollen saturation in blueberry. HortScience, 27(10), 1105-1107.

32. Pinzauti, M., Lazzarini, D. \& Felicioli, A. (1997). Preliminary investigation of Osmia cornuta Latr. (Hymenoptera, Megachilidae) as a potential pollinator for blackberry (Rubus fruticosus L.) under confined environment. Acta Horticulturae 437, 329-333. 
33. Potts, S. G., Biesmeijer, J. C., Kremen, C., Neumann, P., Schweiger, O., \& Kunin, W. E. (2010). Global pollinator declines: Trends, impacts and drivers. Trends in Ecology \& Evolution, 25(6), 345-353.

34. R Core Team. (2012). R: A language and environment for statistical computing. R Foundation for Statistical Computing, Vienna, Austria. ISBN 3-900051-07-0, URL http://www.R-project.org/

35. Raw, A. (1972). The biology of the solitary bee Osmia rufa (Megachilidae). Transitions of the Royal Entomological society of London, 124(3), 213-229.

36. Ricketts, T. H.; Regetz, J.; Steffan-Dewenter, I.; Cunningham, S. A.; Kremen, C.; Bogdanski, A.; Gemmill-Herren, B.; Greenleaf, S. S.; Klein, A. M.; Mayfield, M. M.; Morandin, L. A.; Ochieng', A.; Potts, S. G.; Viana. B. F. (2008). Landscape effects on crop pollination services: are there general patterns? Ecology Letters 11, 499-515.

37. Royal Horticultural Society. (2016). Prunus avium "Stella".: Retrieved from https://www.rhs.org.uk/Plants/59056/Prunus-avium-Stella-(F)/Details

38. Sainsbury's Supermarkets Ltd.. (2015). Quality attribute sheet. V9.0. Cherry punnet 225G. Supermarkets Ltd. London.

39. Sedivy, C., \& Dorn, S. (2014). Towards a sustainable management of bees of the subgenus Osmia (Megachilidae; Osmia) as fruit tree pollinators. Apidologie, 45(1), 88-105. 
40. Sekita, N. (2000). Managing Osmia cornifrons to pollinate apples in Aomori Prefecture, Japan. In P. Benedek \& K.W. Richards (Eds.), ICNPS 2000. Proceedings of the VIII International Symposium on Pollination: Integrator of Crops and Native Plant Systems (pp. 303-307). Mosonmagyaróvár, Hungary: International Society for Horticultural Science.

41. Sekita, N., \& Yamada, M. (1993). Use of Osmia cornifrons for pollination of apples in Aomori Prefecture, Japan. Japan Agricultural Research Quarterly, 26, 264-264.

42. Soilscapes. (2016). Cranfield Soil and Agrifood Institute. Retreived from: http://www.landis.org.uk/soilscapes/

43. Stephenson, A.G. (1980). Fruit Set, Herbivory, Fruit Reduction and the Fruiting Strategy of Catalpa Speciosa (Bignoniaceae). Ecological Society of America, 61(6), 57-64

44. Stone, G., \& Willmer, P. (1989). Warm-up rates and body temperatures in bees: The importance of body size, thermal regime and phylogeny. Journal of Experimental Biology, 147(1), 303-328.

45. Teper, D., \& Bilinski, M. (2009). Red mason bee (Osmia rufa L.) as a pollinator of rape plantations. Journal of Apicultural Science, 2(53), 115-120.

46. Torchio, P. F., \& Asensio, E. (1985). The introduction of the European bee, Osmia cornuta latr., into the US as a potential pollinator of orchard crops, and a comparison of its manageability with Osmia lignaria propinqua cresson 
600

601

602

603

604

605

606

607

608

609

610

611

(Hymenoptera: Megachilidae). Journal of the Kansas Entomological Society, $58(1), 42-52$.

47. Ughini, V., \& Roversi, A. (1993). Investigations on sweet cherry effective pollination period. In C.R. Hampson, R.L. Anderson, R.L. Perry, A.D. Webster (Eds.),ICS 1993. Proceedings of the 2nd International Cherry Symposium (pp. 423-426). Budapest, Hungary: International Society for Horticultural Science.

48. Vanbergen, A. J., Heard, M. S., Breeze, T., Potts, S. G., Hanley, N. (2014). Status and value of pollinators and pollination services. A report to the Department for Environment, Food and Rural Affairs (Defra). Retrieved from: https://www.researchgate.net/profile/Adam_Vanbergen/publication/283288659_ Status_and_value_of_pollinators_and_pollination_services/links/5630b2e708ae 336c42eb53aa/Status-and-value-of-pollinators-and-pollination-services.pdf

49. Wilkaniec, Z., \& Radajewska, B. (1996). Solitary bee Osmia rufa L.(Apoidea, Megachilidae) as pollinator of strawberry cultivated in an unheated plastic tunnel. Acta Horticulturae, 439; DOI: 10.17660/ActaHortic.1997.439.83 https://doi.org/10.17660/ActaHortic.1997.439 $\underline{.8}$

50. Winfree, R.; Aguilar, R.; Zquez, D. P. Va; Lebuhn, G. \& Aizen, M. A.(2009). A meta-analysis of bees' responses to anthropogenic disturbance. Ecology 90, 2068-2076. 
612

613

614

615

616

617

618

619

620

621

622

623

624

625

626

627

628

629
51. Zhang, C., Tateishi, N., \& Tanabe, K. (2010). Pollen density on the stigma affects endogenous gibberellin metabolism, seed and fruit set, and fruit quality in Pyrus pyrifolia. Journal of Experimental Botany, 61(15), 4291-4302. 


\section{Table captions}

631 Table 1: The abundance of wild pollinators in the cherry orchard in 2015 and 2016.

632 Figures for each treatment/insect category are the mean of 60 assessments (three standard 633 sweep net samples taken in each of four treatment replicates, on each of five days) taken

634 during the flowering period of the orchard. Insects were recorded under six categories, 635 wild (non-O.bicornis) solitary bees, bumblebees (Bombus spp.), honey bees (Apis 636 mellifera), hoverflies (Syrphidae), "other" diptera, and "other" insects (Hymenoptera 637 (mainly parasitoids, Coleoptera and Neuroptera).

638

\section{Figure captions}

640 Figure 1:- Mean ( \pm standard error) number of buds in 2015 (A) and 2016 (B), proportion 641 of fruit set in 2015 (C) and 2016 (D), and mean total number fruit set in 2015 (E) and

6422016 (F) on 50cm lengths of branch in Osmia supplemented and wild pollinator

643 treatments. Treatments sharing the same letter did not vary significantly from each other $644(\mathrm{p}>0.05)$

645 Figure 2:- Increase in fruit width (mm) with time (sample week) in 2015 (A) and 2016 646 (B). $+/-=$ Osmia supplemented treatment; $\mathrm{x} /$--- = wild pollinator treatment.

647 Figure 3:- Mean ( \pm standard error) fruit weight (g) in 2015 (A) and 2016 (B), and mean 648 fruit width (mm) in 2015 (C) and 2016 (D), on $50 \mathrm{~cm}$ lengths of branch in Osmia 649 supplemented and wild pollinator treatments. Treatments sharing the same letter did not 650 vary significantly from each other $(\mathrm{p}>0.05)$ 
651 Figure 4:- Mean ( \pm standard error) post-harvest sugar content (\% Brix) in 2015 (A) and 652 2016(B), and consistency (pressure required to penetrate the fruit expressed as percentage 653 of maximum pressure exerted by the penetrometer) in 2015 (C), on $50 \mathrm{~cm}$ lengths of 654 branch in Osmia supplemented and wild pollinator treatments. Treatments sharing the 655 same letter did not vary significantly from each other $(\mathrm{p}>0.05)$

656 Figure 5:- Mean ( \pm standard error) post-harvest colour measurements (Industry standard 657 scale) in 2015 (A) and 2016 (B), on 50cm lengths of branch in Osmia supplemented and 658 wild pollinator treatments. Treatments sharing the same letter did not vary significantly 659 from each other $(\mathrm{p}>0.05)$

660

661

662

663

664

665

666

667

668

669 
671 Table 1:

672

\begin{tabular}{|c|c|c|c|c|c|c|c|}
\hline Year & Treatment & $\begin{array}{c}\text { Wild } \\
\text { solitary } \\
\text { bees }\end{array}$ & $\begin{array}{c}\text { Bombus } \\
\text { spp. }\end{array}$ & $\begin{array}{c}\text { Apis } \\
\text { mellifera }\end{array}$ & $\begin{array}{l}\text { Syrphidae } \\
\text { spp. }\end{array}$ & $\begin{array}{c}\text { Other } \\
\text { Diptera }\end{array}$ & Other insects \\
\hline \multirow[t]{2}{*}{2015} & $\begin{array}{l}\text { Osmia } \\
\text { supplemented }\end{array}$ & 0 & 0 & 0.03 & 0.08 & 0 & 0 \\
\hline & $\begin{array}{l}\text { Wild } \\
\text { pollinator }\end{array}$ & 0.02 & 0.02 & 0.07 & 0.23 & 0 & 0 \\
\hline \multirow[t]{2}{*}{2016} & $\begin{array}{l}\text { Osmia } \\
\text { supplemented }\end{array}$ & 0.12 & 0.03 & 0.2 & 0.08 & 2.48 & 0.83 \\
\hline & $\begin{array}{l}\text { Wild } \\
\text { pollinator }\end{array}$ & 0.18 & 0.02 & 0.35 & 0.13 & 1.88 & 1.0 \\
\hline
\end{tabular}

673

674

675

676

677

678

679

680

681 
Figure 1:

A

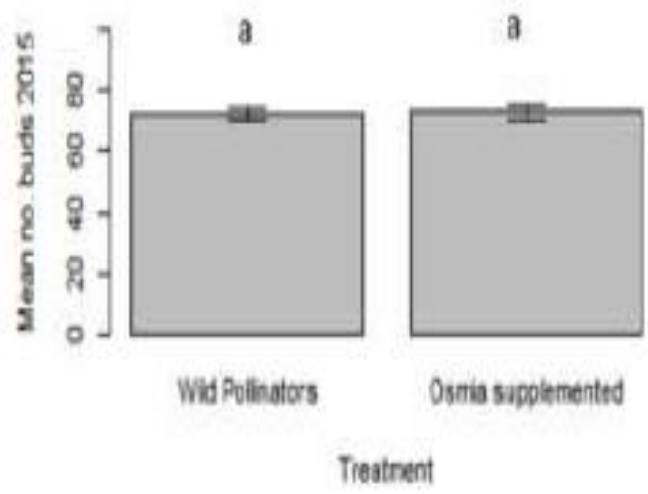

C

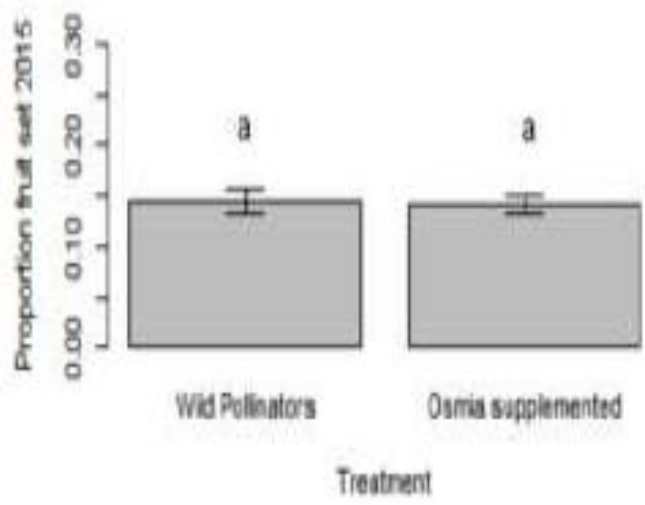

E

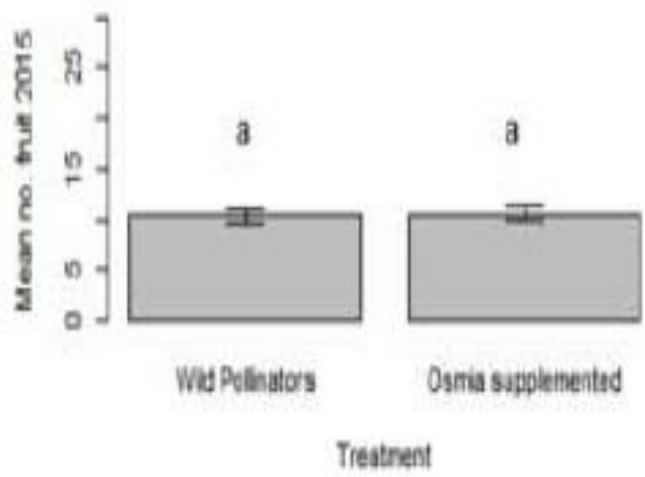

B

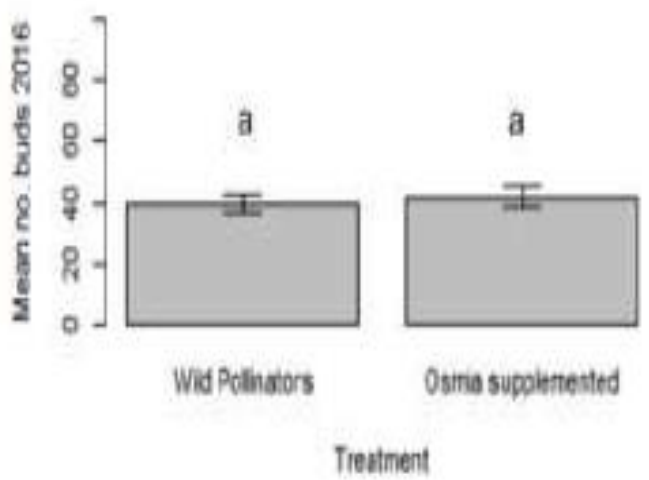

D

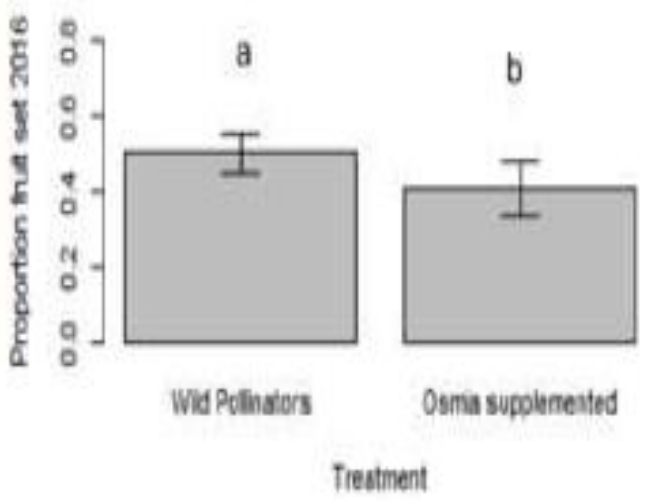

F

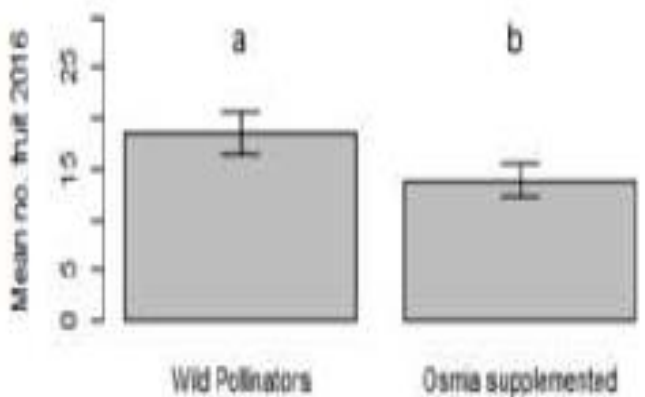

Treatment

683

684 
Figure 2:
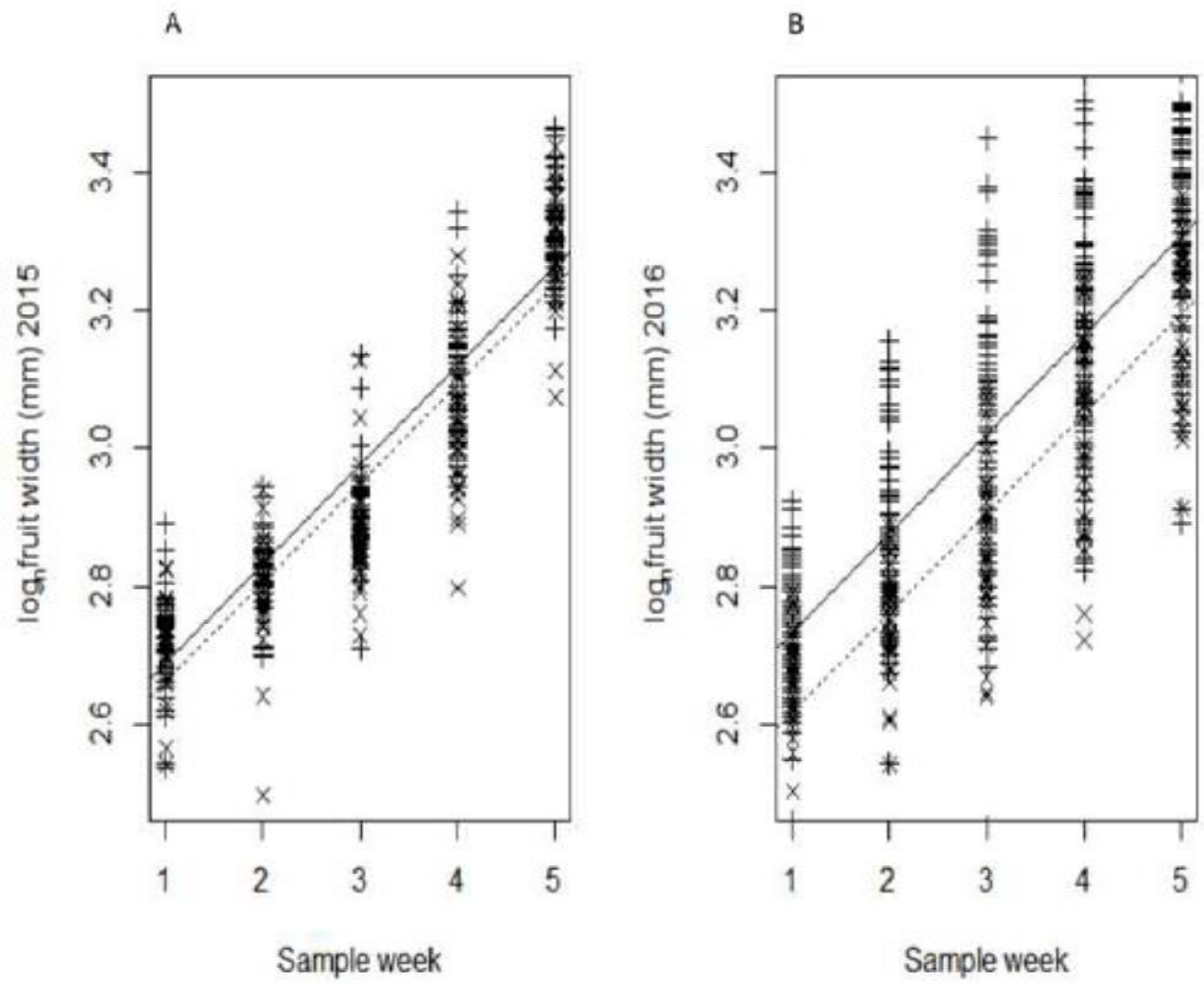

686

687

688

689

690

691

692

693 

Figure 3:

A

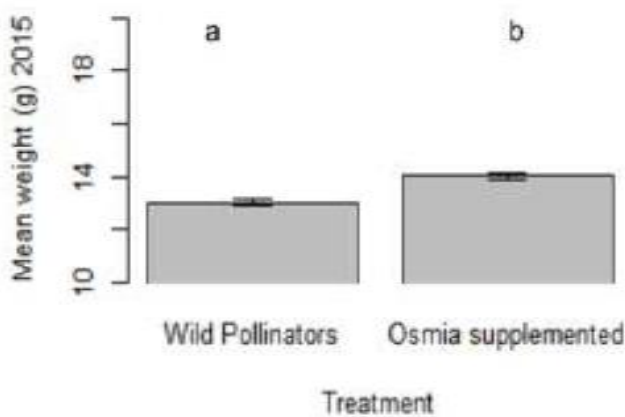

C

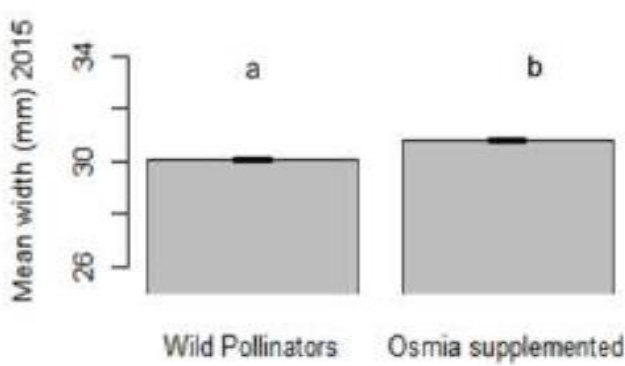

Treatment
B

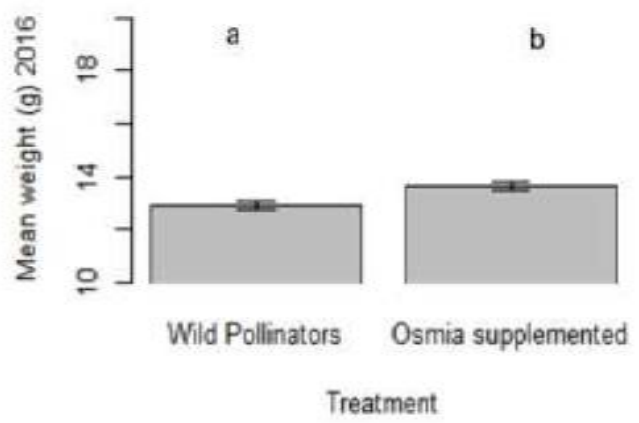

D

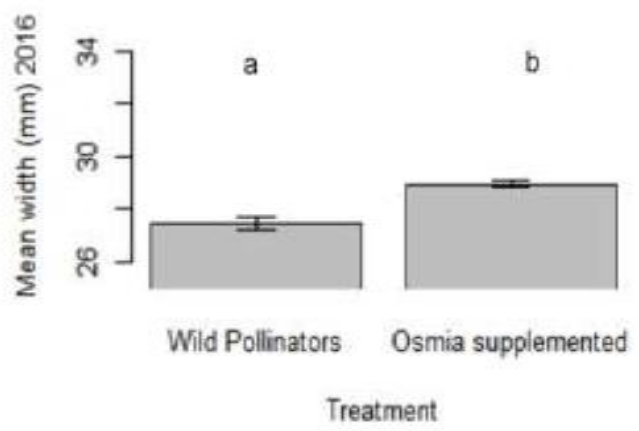

695

696

697

698

699

700

701

702 

Figure 4:

A

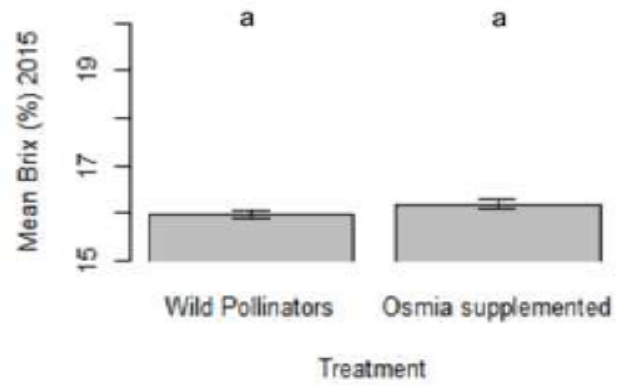

C

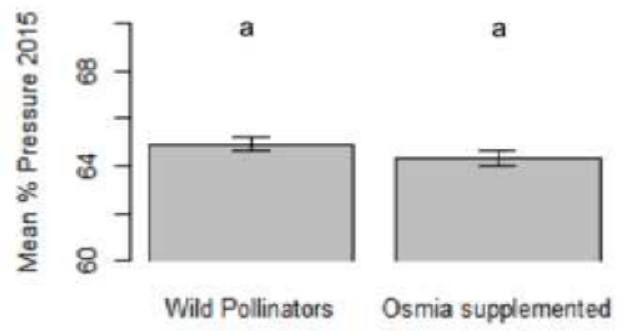

704

705

706

707

708

709

710

711

712

Treatment

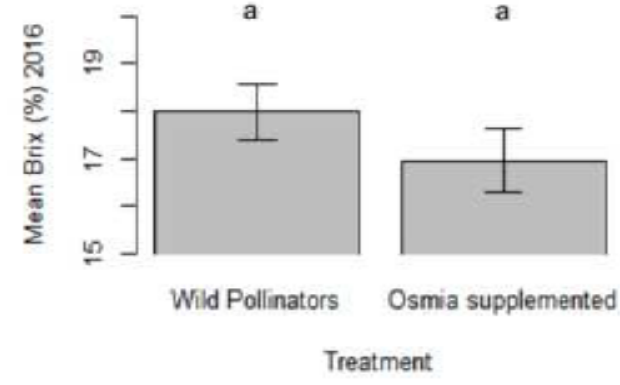


Figure 5:

A

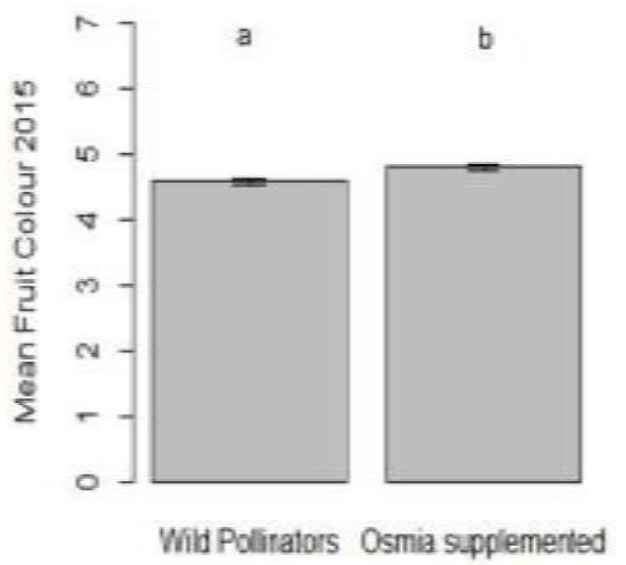

Treatmert
B

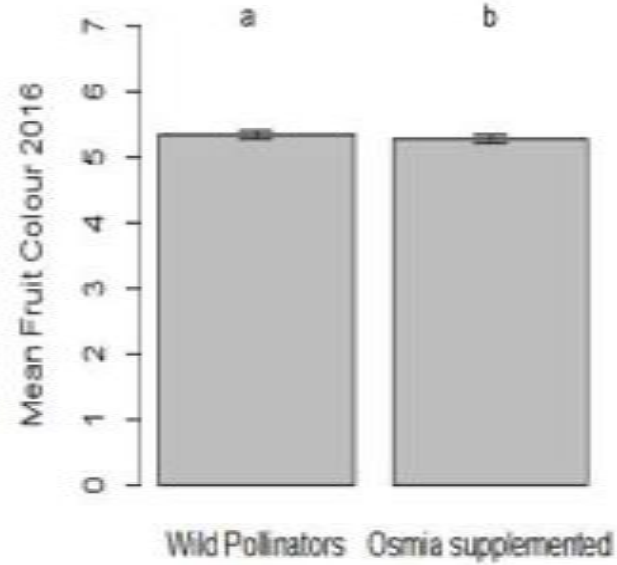

Treatment

714 